\title{
EFEITO DOS ÁCIDOS INDOLBUTÍRICO E NAFTALENOACÉTICO NO ENRAIZAMENTO DE ESTACAS SEMILENHOSAS DE Cordia trichotoma (Vell.) Arrab. ex Steud.
}

\section{EFFECTS OF THE INDOLBUTIRIC AND NAPHTHALENEACETIC ACIDS ON THE ROOTING OF Cordia trichotoma (Vell.) Arrab. ex Steud. SEMI-WOODY CUTTINGS}

\author{
Luiz Roberto Faganello ${ }^{1}$ João Alexandre Lopes Dranski ${ }^{2}$ Ubirajara Contro Malavasi ${ }^{3}$ \\ Marlene de Matos Malavasi ${ }^{4}$
}

\begin{abstract}
RESUMO
O presente trabalho objetivou avaliar os efeitos de diferentes concentrações de ácido indolbutírico e do ácido $\alpha$-naftaleno acético no enraizamento de estacas semilenhosas coletadas de brotações de mudas de Cordia trichotoma. As mudas foram produzidas por sementes, constituindo um jardim miniclonal com posterior poda da parte aérea. As brotações foram colhidas resultando em estacas semilenhosas com 12,0 $\mathrm{cm}$ de comprimento e, $5,5 \mathrm{~mm}$ de diâmetro e um par de folhas na porção apical reduzida pela metade. Os tratamentos compreenderam a imersão rápida da base das estacas em ácido indolbutírico (AIB) e ácido $\alpha$-naftaleno acético (ANA) nas concentrações de 0, 2.000, 4.000, 6.000, $8.000 \mathrm{mg} \mathrm{L}^{-1}$ em delineamento de blocos casualizados com arranjo bifatorial 2 × 5. Após 60 dias do estaqueamento, foram avaliados a porcentagem de enraizamento, o número e comprimento das raízes, a porcentagem de brotações, o número de brotos e folhas novas, a porcentagem de estacas com calos, assim como a sobrevivência e mortalidade. O fitorregulador AIB na concentração de $8.000 \mathrm{mg} \mathrm{L}^{-1}$ promoveu maior enraizamento, resultando em $28,9 \%$ das estacas enraizadas, e com maior número de raízes por estaca. Para o ANA, não houve efeito significativo sobre o enraizamento. $\mathrm{O}$ aumento crescente da concentração dos fitorreguladores reduziu linearmente a emissão de brotações e folhas novas e aumentou linearmente a mortalidade de estacas, afetando negativamente os componentes da parte aérea das estacas semilenhosas de Cordia trichotoma.

Palavras-chave: Louro-pardo; propagação vegetativa; estaquia; fitorreguladores.
\end{abstract}

\section{ABSTRACT}

This study aimed to evaluate the effects of different concentrations of the indolbutiric acid and $\alpha$-naphthalene acetic acid on the rooting of semi-woody cuttings, collected from the sprout of Cordia trichotoma seedlings. Seedlings were produced by seeds constituting a miniclonal garden with subsequent pruning of the aerial part. Sprouts were harvested resulting in semi-woody cuttings with $12.0 \mathrm{~cm}$ long and $5.5 \mathrm{~mm}$ in diameter and a pair of leaves in the apical portion reduced in a half. The treatments consisted of fast immersion of the cuttings base in indolbutiric acid (IBA) and $\alpha$-naphthalene acetic acid (NAA) in concentrations of $0,2.000,4.000,6.000,8.000 \mathrm{mg} \mathrm{L}^{-1}$ in a randomized block design with bifactorial arrangement $2 \times 5$. After 60 days of cutting, rooting percentage, roots number and length, sprouting percentage, the number of shoots and new leaves were evaluated as well as the survival and mortality. The phytoregulator IBA at

1 Engenheiro Agrônomo, MSc., Instituto Paranaense de Assistência Técnica e Extensão Rural, Rua Fortaleza, 408, São Pedro do Iguaçu (PR), Brasil, CEP 85929-000, luizfaganello@emater.pr.gov.br

2 Biólogo, Dr., Pós-doutorando pela Universidade Estadual do Oeste do Paraná, Rua Pernambuco 1777, CEP 85960-000, Marechal Cândido Rondon (PR), Brasil. Bolsista da Fundação Araucária. joaodranski@yahoo.com.br

3 Engenheiro Florestal, Dr., Professor Associado do Centro de Ciências Agrárias, Universidade Estadual do Oeste do Paraná, Rua Pernambuco 1777, CEP 85960-000, Marechal Cândido Rondon (PR), Brasil. Bolsista do CNPq. biramalavasi@yahoo.com.br

4 Engenheira Agrônoma, Dra ${ }^{\mathrm{a}}$, Professora Associada do Centro de Ciências Agrárias, Universidade Estadual do Oeste do Paraná, Rua Pernambuco 1777, CEP 85960-000, Marechal Cândido Rondon (PR), Brasil. Bolsista do CNPq. marlenemalavasi@yahoo.com.br

Recebido para publicação em 17/11/2011 e aceito em 25/02/2014 
a concentration of $8.000 \mathrm{mg} \mathrm{L}^{-1}$ promoted greater rooting, resulting in $28.9 \%$ of the cutting rootings, and greater number of roots per cutting. For the NAA, there was no significant effect on rooting. The increasing concentration of phytoregulators linearly reduced the emission of new leaves and shoots, and increased linearly cutting mortality, negatively affecting the components of the shoot of semi-woody cuttings of Cordia trichotoma.

Keywords: Cordia trichotoma; vegetative propagation; phytoregulators.

\section{INTRODUÇÃO}

Plantios comerciais de espécies lenhosas nativas têm utilizado mudas produzidas a partir de sementes, que resultam em povoamentos heterogêneos e que dificultam operações de manejo. Portanto, o melhoramento genético de espécies lenhosas nativas reveste-se de importância em função da inexistência de identificação e seleção de genótipos de alta qualidade que possam ser propagados (CLEMENT, 2001).

A propagação vegetativa via estaquia caracteriza-se como um dos métodos mais importantes da propagação de espécies lenhosas devido à maior uniformidade no desenvolvimento da muda e ausência de variabilidade genética dos clones produzidos, permitindo a fixação de genótipos selecionados (HOPPE et al., 1999; HIGASHI et al., 2000; INOUE e PUTTON, 2007; HEBERLE, 2010).

Para a implantação de povoamentos para fins ambientais existe a necessidade de produzir mudas com variabilidade genética. Porém, muitas espécies lenhosas nativas apresentam baixa porcentagem de germinação. Alternativamente, a estaquia efetuada por meio da coleta de brotações oriundas de mudas produzidas por sementes pode ser empregada (WENDLING et al., 2005).

Em espécies lenhosas, a aptidão para o enraizamento de estacas está associada ao grau de maturação. Na fase juvenil, plantas apresentarem maior potencial de enraizamento em relação à fase adulta (HARTMANN et al., 2002). Face às dificuldades de enraizamento do material maduro, o rejuvenescimento de células e tecidos é provavelmente um dos mais importantes aspectos para o alcance efetivo da propagação vegetativa (BIASI, 1996; MESÉN, 1997). Assim, a técnica de estaquia com propágulos juvenis constitui-se em uma opção interessante já que estacas retiradas de árvores adultas enraízam com dificuldades (GRATIERI-SOSSELLA et al., 2008; XAVIER et al., 2009; HEBERLE, 2010).
A propagação vegetativa é um processo baseado no princípio fisiológico da totipotência. Este princípio retrata que todas as células vivas têm a capacidade ou potencial de reproduzir um organismo inteiro, desde que possuam condições adequadas e informações genéticas necessárias para ocorram às transformações morfogenéticas (HARTMANN et al., 2002; XAVIER et al., 2009) possibilitando a regeneração de raízes, ramos, folhas, e embriões (TAIZ e ZEIGER, 2009).

A iniciação de raízes adventícias é estimulada por altos níveis de auxina que estimulam a divisão celular até formar meristema apical da raiz (TAIZ e ZEIGER, 2009). Os reguladores vegetais mais efetivos como indutores da formação de raízes adventícias em estacas são as auxinas. O ácido indolbutírico (AIB) e o ácido $\alpha$-naftaleno acético (ANA) em aplicação exógena mostram-se bastante eficientes para promover crescimento de raízes (FACHINELLO et al., 2005). Entretanto, a resposta da planta à auxina endógena ou exógena varia tanto com a natureza do tecido, época do ano, condições fisiológicas da planta e da estaca, quanto com a concentração da substância presente (XAVIER et al., 2009).

Cordia trichotoma (Vell.) Arrab. ex Steud., popularmente conhecida como louro-pardo, pertence às Boraginaceas. É uma planta lenhosa, caducifólia, heliófita e de ocorrência natural na América Latina, empregada para fins madeireiros e ambientais. No Brasil, ocorre desde o Ceará até o Rio Grande do Sul. A espécie possui hábito de crescimento monopodial, podendo atingir na idade adulta cerca de $35 \mathrm{~m}$ de altura e $100 \mathrm{~cm}$ de diâmetro a altura de 1,3 m com tronco retilíneo, de seção ovalada a cilíndrica e fuste bem definido, que atinge até a altura de $15 \mathrm{~m}$. A espécie é polígama, com flores masculinas e hermafroditas, polinizadas especialmente por abelhas, que a torna com aptidão apícola. Sua produtividade volumétrica é acima de $20 \mathrm{~m}^{3} \mathrm{ha}^{-1}$ ano $^{-1}$ em solos de média a alta fertilidade, com o primeiro corte estimado aos 15 anos (CARVALHO, 2003; CARPANEZZI 
e CARPANEZZI, 2006; FICK, 2007; HEBERLE, 2010).

A propagação de Cordia trichotoma pode ser efetuada por via seminífera. Porém, a produção comercial de mudas é limitada visto que as sementes apresentam baixa longevidade, com perda da viabilidade em até cinco meses após a colheita, além de germinação lenta e irregular, podendo perdurar por até 90 dias (MANTOVANI et al., 2001; MENDONÇA et al., 2001; LORENZI, 2002; CARVALHO, 2003; FRANZON et al., 2004).

Diante do exposto, o presente trabalho objetivou avaliar os efeitos de concentrações do ácido indolbutírico e do ácido $\alpha$-naftaleno acético no enraizamento de estacas semilenhosas coletadas de brotações de mudas de Cordia trichotoma.

\section{MATERIAL E MÉTODOS}

$\mathrm{O}$ experimento foi instalado em área com coordenadas geográficas de $24^{\circ} 33^{\prime} 25^{\prime \prime} \mathrm{S}$ e $54^{\circ} 02^{\prime} 54^{\prime}$ 'W, e altitude de $415 \mathrm{~m}$. O clima é classificado segundo Köppen do tipo $\mathrm{Cfa}$, subtropical com chuvas bem distribuídas durante o ano e verões quentes. As temperaturas médias do ar do trimestre mais frio variam entre 17 e $18^{\circ} \mathrm{C}$, e do trimestre mais quente entre 28 e $29^{\circ} \mathrm{C}$, enquanto a anual está entre 22 e $23^{\circ} \mathrm{C}$. Os totais de chuva variam entre 1.600 e 1.800 $\mathrm{mm}$ com trimestre mais úmido apresentando totais variando entre 400 e $500 \mathrm{~mm}$ (IAPAR, 2012).

O delineamento experimental foi o de blocos ao acaso em esquema bifatorial 2 x 5 constituído por dois reguladores vegetais (AIB e ANA) e cinco concentrações $(0,2.000,4.000,6.000$ e 8.000 $\mathrm{mg} \mathrm{L}^{-1}$ ) sendo cada combinação dos fatores composta por quatro repetições de 12 estacas. O material vegetal de origem seminal foi produzido em viveiro com coordenadas geográficas de $24^{\circ} 40^{\prime} 35^{\prime \prime} \mathrm{S}$ e $53^{\circ} 42^{\prime} 40^{\prime}$ 'W e altitude de $515 \mathrm{~m}$.

Em setembro de 2010, 15 meses após a semeadura, 480 mudas foram selecionadas e transplantadas para tubetes de $3,8 \mathrm{dm}^{3}$ preenchidos com substrato comercial com natureza física farelado médio, fertilizado com $100 \mathrm{~g}$ do formulado $\mathrm{N}_{2}-\mathrm{P}_{2} \mathrm{O}_{5}$ $\mathrm{K}_{2} \mathrm{O}$ (4-20-20) acrescido de $100 \mathrm{~g}$ do fertilizante de liberação controlada Basacote ${ }^{\circledR}$ Mini 6 meses da formulação $\mathrm{N}_{2}-\mathrm{P}_{2} \mathrm{O}_{5}-\mathrm{K}_{2} \mathrm{O}$ (13-6-16) para $25 \mathrm{~kg}$ de substrato. As mudas receberam adubação em cobertura a cada 30 dias com o formulado comercial Triabon $^{\circledR}$ da formulação $\mathrm{N}_{2}-\mathrm{P}_{2} \mathrm{O}_{5}-\mathrm{K}_{2} \mathrm{O}$ (16-8-12) na dose de $15 \mathrm{~g}$ por muda.

O manejo do jardim miniclonal constituiu- se, principalmente, de irrigações diárias e do controle manual de plantas concorrentes a cada 21 dias. Em dezembro de 2010, o jardim miniclonal foi podado a $20 \mathrm{~cm}$ da base das mudas para emissão de brotações. Estacas caulinares semilenhosas foram coletadas em fevereiro de 2011 quando externaram $5,5 \mathrm{~mm}$ de diâmetro e $12 \mathrm{~cm}$ de comprimento em média, as quais foram colocadas úmidas em caixa de isopor e transportadas para o laboratório, quando foram lavadas em água corrente durante $5 \mathrm{~min}$.

A desinfecção das estacas foi realizada com a imersão em solução de hipoclorito de sódio $0,5 \%$ por $5 \mathrm{~min}$, seguida de lavagem em água corrente por 5 min. Ao término, a base de cada estaca foi imersa em solução com fungicida sistêmico $\left(\right.$ Cerconil $^{\mathbb{R}}$ $\mathrm{WP}, 1,0 \mathrm{~g} \mathrm{~L}^{-1}$ ) por $15 \mathrm{~min}$. $\mathrm{O}$ material propagativo recebeu corte em bisel na base, reto no ápice, com um par de folhas cortadas transversalmente ao meio, antecedendo a aplicação dos reguladores.

As bases das estacas de Cordia trichotoma sofreram imersão rápida (10 s) em AIB ou ANA nas concentrações de $0,2.000,4.000,6.000$ e $8.000 \mathrm{mg}$ $\mathrm{L}^{-1}$ diluído em álcool etílico a $50 \%$. A testemunha usada como tratamento controle foi imersa somente no álcool etílico a $50 \%$.

Os propágulos foram estaqueados em tubetes de $120 \mathrm{~cm}^{3}$ de volume preenchidos com uma mistura de 50\% de vermiculita (granulometria média), 25\% de vermiculita (granulometria fina) e $25 \%$ de casca de arroz carbonizada. Os tubetes foram dispostos de forma alternada em suportes plásticos com capacidade para 96 tubetes, e mantidos em ambiente protegido recoberto com tela de sombreamento (50\%) e, sob este com lona plástica transparente de $150 \mu \mathrm{m}$ para evitar a água das chuvas. $\mathrm{O}$ ambiente foi monitorado quanto à temperatura e umidade relativa do ar com um termohigrômetro instalado a $50 \mathrm{~cm}$ acima dos aspersores, em uma das extremidades da estrutura do ambiente, cujas leituras foram registradas a cada hora durante $24 \mathrm{~h}$ durante todo o período do ensaio (Figura 1).

$$
\text { Adicionalmente, a radiação }
$$

fotossinteticamente ativa foi medida no mês de março de 2011 em dia ensolarado e nebuloso, dentro e fora da estufa com o auxílio do LI-250A Light Meter, cujos valores foram expressos em $\mu \mathrm{mol}$ de fótons $\mathrm{s}^{-1} \mathrm{~m}^{-2}$.

Empregou-se irrigação com microaspersão acionada automaticamente através de um temporizador digital com oito programações diárias (das $7 \mathrm{~h}$ às $18 \mathrm{~h}$ ), com $3 \mathrm{~min}$ por vez, assim distribuídas: 7h; 9h; 10h30; 12h; 13h30; 15h; 16h30 


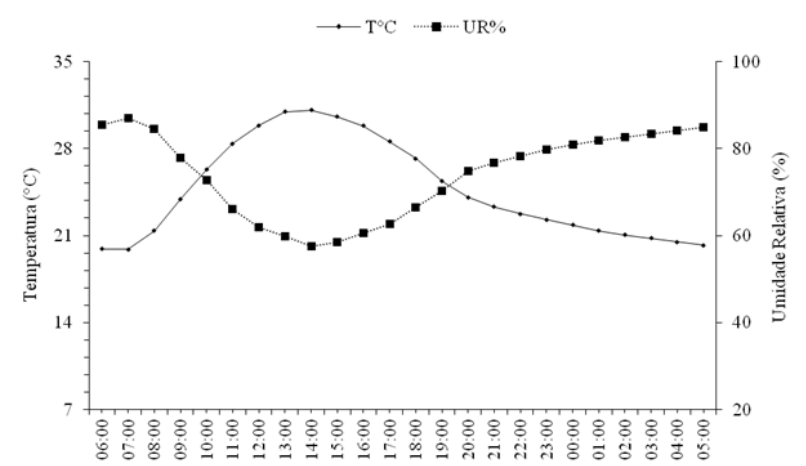

FIGURA 1: Médias de temperatura e umidade relativa do ar por horário ao longo do dia no ambiente propagativo de 19/02/2011 a 21/04/2011.

FIGURE 1: Average temperature and relative humidity for hours throughout the day in the propagative environment $19 / 02 / 2011$ to $21 / 04 / 2011$.

e 18h. O conjunto irrigação, composto por um depósito de água de 1.000 L., motobomba elétrica de $1 / 2$ HP, um contator de eletricidade acionado pelo temporizador, dois microaspersores Ma20 $\left(\mathrm{MecPrec}^{\circledR}\right)$, um cano mestre de PVC na horizontal e duas hastes perpendiculares em tubulação de 20 $\mathrm{mm}$. Os aspersores foram dispostos a $1,20 \mathrm{~m}$ de distância entre si e $0,35 \mathrm{~m}$ acima das estacas com vazão média de $0,63 \mathrm{~mm}$ minn $^{-1}$.

Após 60 dias do estaqueamento, quantificou-se a porcentagem de enraizamento das estacas (considerou-se a estaca enraizada aquela que apresentava pelo menos uma raiz maior que $2 \mathrm{~mm}$ de comprimento), a porcentagem de sobrevivência (estacas vivas que não formaram raízes e nem calos); e a porcentagem de estacas mortas (estacas com tecidos necrosados). Adicionalmente, anotouse por estaca o número de raízes, de calos, de brotações, de folhas emitidas após o estaqueamento, além da mensuração do comprimento médio das três maiores raízes e o comprimento dos brotos emitidos ambos expressos em centímetros.

Os dados obtidos foram averiguados quanto à normalidade da distribuição dos resíduos pelo teste de Lilliefors, e homogeneidade da variância pelo teste de Cochran \& Bartlett, e submetidos à análise de variância com o auxílio do software SAEG (SAEG, 2007). Quando da existência de diferenças significativas, as médias foram comparadas pelo teste de Tukey ao nível de 5\% de probabilidade de erro e análise de regressão polinomial ao nível de $1 \%$ de probabilidade de erro.

\section{RESULTADOS E DISCUSSÃO}

Em um dia ensolarado, a radiação fotossinteticamente ativa (RFA) variou de 314,40 a 770,00 $\mu \mathrm{mol}$ de fótons $\mathrm{s}^{-1} \mathrm{~m}^{-2}$ internamente ao ambiente de propagação, enquanto a externa variou de 561,00 a $2.771,00 \mu \mathrm{mol}$ de fótons $\mathrm{s}^{-1} \mathrm{~m}^{-2}$, ou seja, a RFA média interna foi $30,1 \%$ da RFA do ambiente. As mesmas quantificações em dia nublado resultaram em valores de 148,80 a $578,40 \mu \mathrm{mol}$ de fótons $\mathrm{s}^{-1} \mathrm{~m}^{-2}$ internamente e de 500,20 a $1.662,40$ $\mu$ mol de fótons $\mathrm{s}^{-1} \mathrm{~m}^{-2}$ no ambiente externo, ou $31,2 \%$ da RFA externa.

$\mathrm{O}$ uso de ambientes de enraizamento com valores inferiores a $150 \mu \mathrm{mol}$ de fótons $\mathrm{s}^{-1} \mathrm{~m}^{-2}$ na maior parte do período diurno, não foi recomendado por Alfenas et al. (2004). No presente trabalho, obteve-se, em dia nublado, 148,8 $\mu \mathrm{mol}$ de fótons $\mathrm{s}^{-1} \mathrm{~m}^{-2}$ ao final da tarde, sendo os demais valores superiores a este para as outras condições do tempo e horário, havendo, assim, ambiente favorável ao enraizamento com relação à luminosidade. A literatura não é clara quanto aos efeitos de diferentes intensidades luminosas sobre o enraizamento de estacas, principalmente em virtude das condições ambientais específicas de cada local (XAVIER et al., 2009).

A análise dos resultados indicou interação $(p<0,05)$ entre os efeitos dos reguladores vegetais com atividade auxínica e aqueles das concentrações para porcentagem de enraizamento, porcentagem de estacas que apenas apresentaram formação de calos, e porcentagem de sobrevivência. $\mathrm{O}$ emprego de AIB aumentou linearmente a porcentagem de miniestacas enraizadas (Figura 2a) com o aumento de sua concentração. O uso de $8.000 \mathrm{mg} \mathrm{L}^{-1}$ resultou em $28,9 \%$ de enraizamento, enquanto no tratamento controle (sem o fitorregulador) ocorreram apenas $2,5 \%$.

Para porcentagem de estacas que apresentaram apenas formação de calos (Figura 2b), observou-se efeito polinomial quadrático $(\mathrm{p}<0,01)$ para o fitorregulador AIB. A máxima concentração estimada pelo ajuste foi de $3.675 \mathrm{mg} \mathrm{L}^{-1}$, a qual proporcionou o máximo de estacas com calos (62\%), o que indica que, acima desta concentração, houve maior diferenciação dos calos para formação de raízes, visto que na porcentagem de enraizamento nesta concentração representou apenas 50,1\%.

$\mathrm{O}$ uso do regulador ANA inibiu a formação 
de calos em estacas de Cordia trichotoma (Figura $2 b)$. Os resultados externaram um efeito linear decrescente $(\mathrm{p}<0,01)$, no qual o emprego de 8.000 mg $\mathrm{L}^{-1}$ de ANA resultou na redução de $38,2 \%$ na porcentagem de estacas com calos em comparação ao tratamento controle.

Para a porcentagem de estacas que não emitiram calos ou raízes e permaneceram vivas (Figura 2c) nota-se que o aumento na concentração do AIB resultou em diminuição abrupta da sobrevivência, com valores próximos de zero de sobrevivência com a concentração de $8.000 \mathrm{mg} \mathrm{L}^{-1}$, indicativo de efeitos do regulador na rizogênese. Sem o emprego do AIB, 43,7\% das estacas não esboçaram qualquer alterações na formação de raízes. O AIB tem apresentado maior eficiência na promoção de raízes adventícias em estacas florestais, visto a sua menor mobilidade e maior estabilidade química no interior da estaca (XAVIER et al., 2009).

Os resultados obtidos contrastam ao reportado por Heberle (2010), no qual não foi observado enraizamento em estacas lenhosas de Cordia trichotoma com a adição de $8.000 \mathrm{mg} \mathrm{L}^{-1} \mathrm{de}$ AIB, coletadas de plantas adultas no final do inverno de 2009. Estacas de espécies lenhosas com maior teor de lignina apresentam maior dificuldade para enraizar, seja pela presença de um anel de esclerênquima contínuo, que pode constituir uma barreira física à emergência das raízes, ou pelo maior grau de maturidade e menor habilidade fisiológica em formar primórdios radiculares a

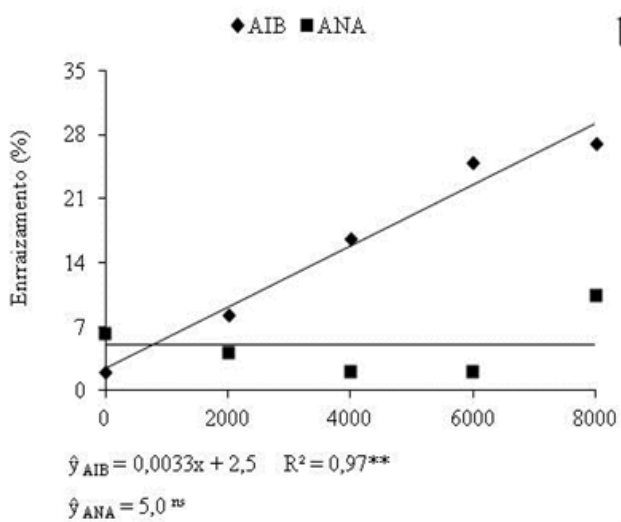

$\mathrm{c}$

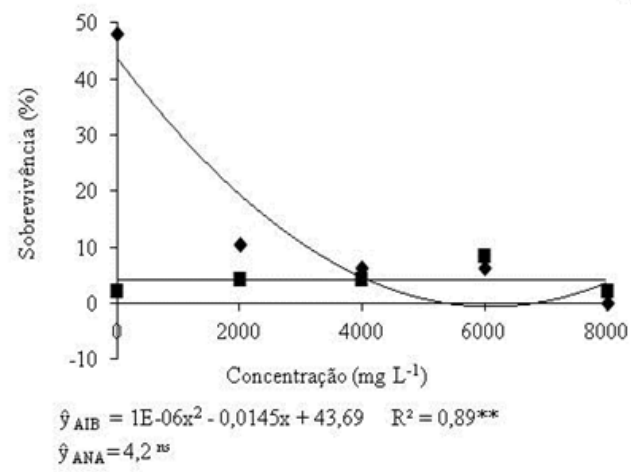

b

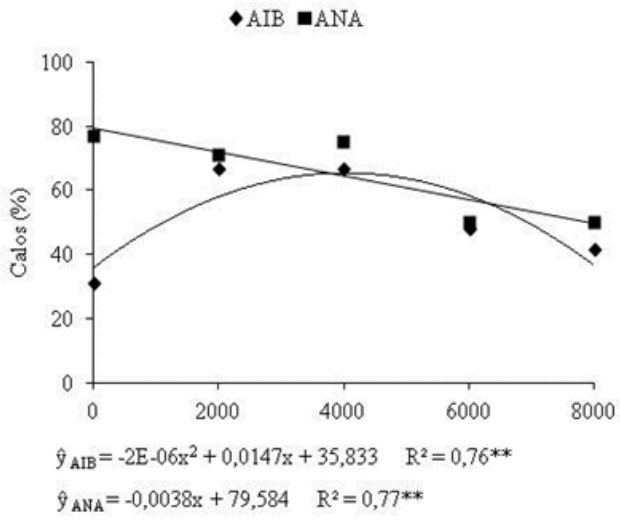

d

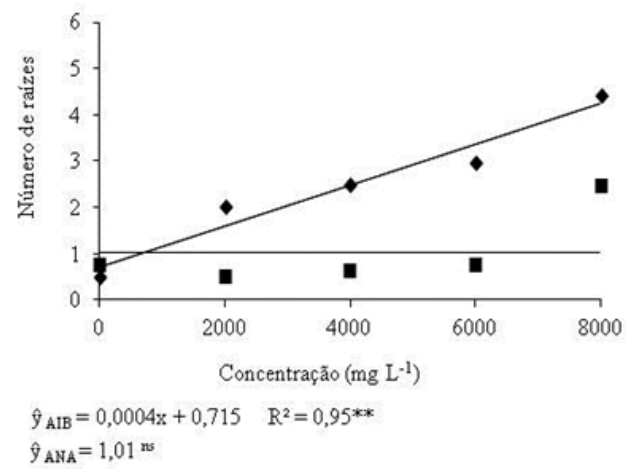

FIGURA 2: (a) Porcentagem de enraizamento, (b) porcentagem de estacas com calos, (c) porcentagem de sobrevivência e (d) número de raízes de estacas semilenhosas, coletadas de brotações de mudas de Cordia trichotoma e submetidas a diferentes concentrações de ácido indolbutírico (AIB) e ácido $\alpha$-naftaleno acético (ANA). ** Significativo ao nível de $1 \%$ de probabilidade de erro; ${ }^{\text {ns }}$ não significativo.

FIGURE 2: (a) Rooting percentage, (b) percentage of cuttings with callus, (c) survival percentage and (d) number of roots of semi-woody cuttings, collected from shoots cuttings collected from the sprout of Cordia trichotoma seedlings and submitted to different concentrations of the indolbutiric acid (IBA) and $\alpha$-naphthalene acetic acid (NAA). ${ }^{* *}$, Significant at the $1 \%$ level of probability; ${ }^{\text {ns }}$ not significant. 
(TOFANELLI, 1999; HARTMANN et al., 2002; XAVIER et al., 2009).

A baixa porcentagem de enraizamento de miniestacas de Cordia trichotoma também foi reportada por Fick (2007) que observou apenas quatro miniestacas enraizadas, quando submetidas a $1.000 \mathrm{mg} \mathrm{L}^{-1}$ de AIB em diversas épocas de propagação (maio de 2006 a abril de 2007), apesar da alta percentagem de sobrevivência e formação de calos. $\mathrm{O}$ mesmo autor atribuiu o fato do não enraizamento às condições ambientais do local do experimento o qual não apresentava controle de temperatura e umidade relativa do ar. Assim, tanto com material lenhoso oriundo de plantas adultas como com material juvenil (miniestacas coletadas de mudas de origem seminal) não houve sucesso na emissão de raízes adventícias para estaquia de Cordia trichotoma. No entanto, o presente experimento constatou que o uso de estacas semilenhosas oriundas de mudas de origem seminal apresenta resultados promissores para a propagação vegetativa da espécie.

A maioria das plantas lenhosas sofre mudanças morfológicas, fisiológicas e bioquímicas durante a transição da fase juvenil para a adulta, principalmente com relação ao potencial de clonagem e vigor de crescimento. A carência de estudos científicos sobre o tema em nível de plantas lenhosas nativas tem dificultado os avanços da propagação vegetativa na silvicultura clonal intensiva. Porém, para algumas espécies lenhosas como Cedrela fissilis Vell., Sapium glandulatum (Vell.) Pax, e Erythrina crista-galli L., a estaquia a partir de material juvenil de origem seminal temse mostrado tecnicamente viável (WENDLING e XAVIER, 2001; XAVIER et al., 2003; GRATIERISOSSELLA et al., 2008; XAVIER et al., 2009; FERREIRA et al., 2010).

O reconhecido efeito da temperatura e da umidade relativa do ar no processo rizogênico pode ser limitante dependendo das condições em que o ambiente propagativo foi mantido. Durante a realização deste experimento, no período compreendido entre $10 \mathrm{~h}$ e $18 \mathrm{~h}$ ocorreu a temperatura máxima de $31,1^{\circ} \mathrm{C}$ e mínima umidade relativa do ar de $57,5 \%$. Estas condições podem ter influenciado negativamente a porcentagem de enraizamento de Cordia trichotoma levando a uma condição de maior transpiração. Bons resultados no enraizamento de espécies lenhosas são obtidos com um amplo intervalo de temperatura que varia de 15 a $35^{\circ} \mathrm{C}$, com faixa ideal entre 25 a $30^{\circ} \mathrm{C}$ (BERTOLOTI e
GONÇALVES, 1980; XAVIER et al., 2009).

No presente ensaio, valores de umidade relativa do ar abaixo de $80 \%$ ocorreram das $9 \mathrm{~h}$ às $21 \mathrm{~h}$ (Figura 1). Em geral, para contornar o problema da transpiração excessiva, Xavier et al. (2009) sugeriram manter a umidade relativa do ar acima de $80 \%$ conservando, assim, a turgescência dos tecidos. Entretanto, deve-se evitar a saturação do ar por dificultar as trocas gasosas, impedir o enraizamento e provocar a morte dos tecidos.

Com o aumento na porcentagem de enraizamento de estacas com o uso de AIB em função das concentrações crescentes, houve aumento linear no número de raízes maiores que $2 \mathrm{~mm}$ (Figura 2d). O uso de $8.000 \mathrm{mg} \mathrm{L}^{-1}$ de AIB resultou em 3,9 raízes por estaca, ou seja, um aumento de $447,5 \%$ no número de raízes, visto que o enraizamento de estacas não submetidas ao regulador (tratamento controle) resultou em apenas 0,71 raízes por estaca. Em estacas de Sapium glandulatum, Ferreira et al. (2010) não encontraram diferenças no número de raízes resultando em média 4,0 raízes quando da adição de ANA ou AIB nas condições do outono.

$\mathrm{Na}$ porcentagem de mortalidade e no comprimento médio de raízes foi detectado apenas efeito $(\mathrm{p}<0,05)$ dos reguladores utilizados. $\mathrm{O}$ uso de AIB resultou em menor mortalidade $(19,2 \%)$ e raízes de maior comprimento $(3,7 \mathrm{~cm}) \mathrm{em}$ comparação ao uso de ANA que resultou em 26,2\% e $1,2 \mathrm{~cm}$ para a mortalidade e comprimento de raiz, respectivamente. ANA é um composto mais ativo e mais fitotóxico que AIB podendo induzir maiores danos por toxidez (ZUFFELLATO-RIBAS e RODRIGUES, 2001; FACHINELLO et al., 2005). Neste caso, isso poderia esclarecer o fato da baixa eficiência do ANA no enraizamento e maior efeito sobre a mortalidade de estacas de Cordia trichotoma.

As variáveis de parte aérea foram influenciadas negativamente pelo aumento das concentrações, independentemente do regulador com atividade auxínica utilizado (Figura 3). Os resultados mostraram haver redução linear $(p<0,05)$ na porcentagem de estacas brotadas (Figura 3a), no número de brotos (Figura 3b) e no número de folhas (Figura 3c). Quando da aplicação de $8.000 \mathrm{mg} \mathrm{L}^{-1}$ apenas $17,3 \%$ das estacas apresentaram brotações, tendo em média 0,8 brotos com 2,7 folhas. As perdas em relação ao controle foram na ordem de $58,2 \%, 36,5 \%$ e $36,9 \%$, para porcentagem de estacas brotadas, número de brotos e número de folhas jovens, respectivamente. 
a

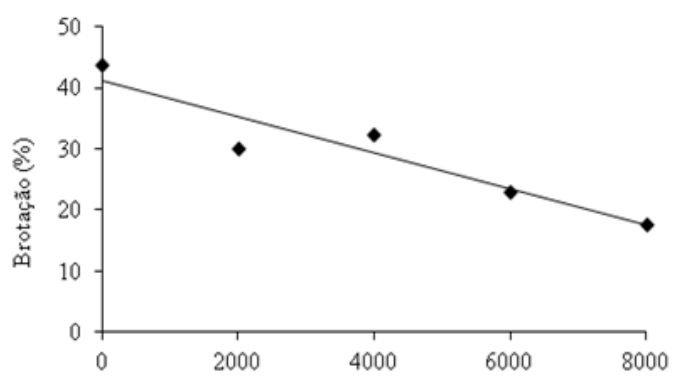

$\hat{y}=-0,003 x+41,25 \quad R^{2}=0,90 * *$

C

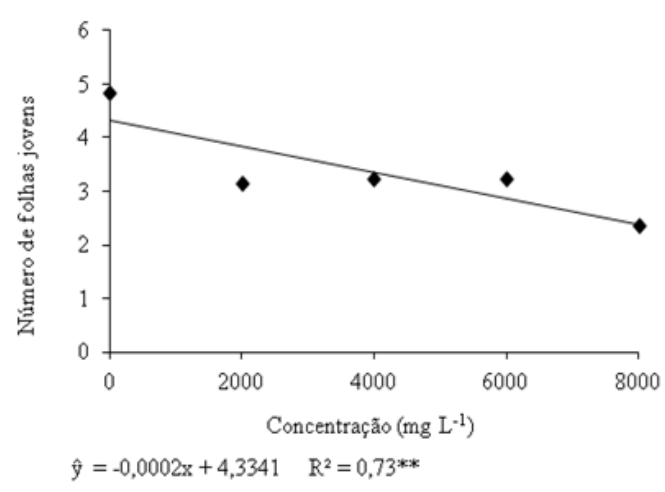

b

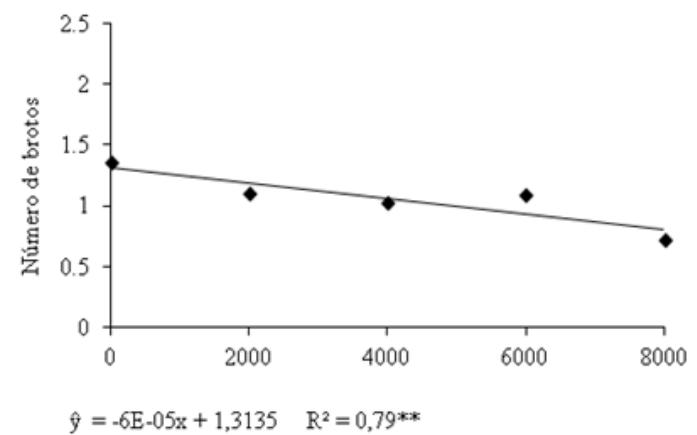

d

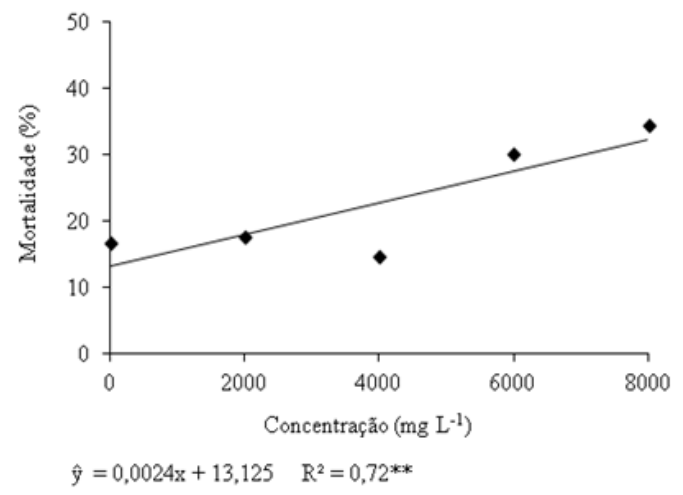

FIGURA 3: Efeito de concentrações crescentes de AIB e ANA em estacas semilenhosas coletadas de brotações de mudas de Cordia trichotoma. (a) Porcentagem de estacas brotadas. (b) Número de brotos. (c) Número de folhas jovens. (d) Mortalidade. ** Significativo ao nível de 1\% de probabilidade de erro.

FIGURE 3: Effect of the IBA and NAA growing concentrations in semi-woody cuttings gathered from sprouts of Cordia trichotoma shoots. (a) Percentage of sprouted cuttings. (b) Number of shoots. (c) Number of new leaves. (d) Mortality. ** Significant at the 1\% level of probability.

O aumento crescente nas concentrações dos reguladores de crescimento testados resultou em um aumento linear da mortalidade das estacas de Cordia trichotoma (Figura 3d) gerando perdas de 32,3\% com a concentração de $8.000 \mathrm{mg} \mathrm{L}^{-1}$. Os resultados para porcentagem de estacas brotadas discordam dos obtidos em outro trabalho com Cordia trichotoma em que não houve efeito significativo quando do emprego de $8.000 \mathrm{mg} \mathrm{L}^{-1}$ de AIB, contudo, após 80 dias houve $100 \%$ de mortalidade (HEBERLE, 2010). O uso de reguladores não apresentou efeito significativo $(\mathrm{p}>0,05)$ para o comprimento médio dos brotos com média de $1,6 \mathrm{~cm}$.

$\mathrm{O}$ processo de fitotoxidez observado na mortalidade indicou que as auxinas, além de serem promotoras do enraizamento, atuam também, na sua inibição quando em concentrações acima das indicadas (HARTMANN et al., 2002; FACHINELLO et al., 2005; NAZÁRIO et al.,
2007). No entanto, a maior evidência pode estar associada ao tipo e à idade do material empregado. O uso de material juvenil através de estacas de origem seminal apresenta-se como uma alternativa viável para enraizamento e estabelecimento de mudas durante todo o ano para algumas espécies lenhosas como Cedrela fissilis e Erythrina cristagalli, respectivamente (GRATIERI-SOSSELLA et al., 2008; XAVIER et al., 2009).

Estudos sobre a propagação vegetativa de Cordia trichotoma por meio da estaquia ainda são incipientes, não fornecendo tecnologia suficiente para o desenvolvimento comercial da técnica. Há, portanto, necessidade de investigações mais aprofundadas sobre o tipo de estaca, época de coleta dos propágulos, nutrição e condições fisiológicas da planta matriz, concentrações e tempo de tratamento com reguladores vegetais, tipo de substrato, e ambiente de propagação para o sucesso 
na propagação da espécie.

\section{CONCLUSÕES}

As concentrações crescentes de ácido indolbutírico e de ácido $\alpha$-naftaleno acético testadas limitaram o desenvolvimento da parte aérea e aumentaram a mortalidade de estacas semilenhosas. A auxina ácido $\alpha$-naftaleno acético foi pouco efetiva na rizogênese. Concentrações elevadas de ácido indolbutírico resultaram na maior porcentagem de enraizamento de estacas de Cordia trichotoma.

\section{AGRADECIMENTOS}

Externamos nossos agradecimentos ao Instituto Paranaense de Assistência Técnica e Extensão Rural e o Instituto Ambiental do Paraná, Núcleo Regional de Toledo - PR, a UNIOESTE pela infraestrutura e apoio logístico. Ao CNPq pelo apoio financeiro ao projeto.

\section{REFERÊNCIAS BIBLIOGRÁFICAS}

ALFENAS, A. C. et al. Clonagem e doenças do eucalipto. Viçosa: UFV, 2004. 442 p.

BERTOLOTI, G.; GONÇALVES, A. N. Enraizamento de estacas: especificações técnicas para construção do módulo de propagação. ESALQ, Piracicaba, 1980. 8 p. (Circular técnica n. 94).

BIASI, L. A. Emprego do estiolamento na propagação de plantas. Ciência Rural, Santa Maria, v. 26, n. 2, p. 309-315, 1996.

CARPANEZZI, A. A.; CARPANEZZI, O. T. B. Espécies nativas recomendadas para recuperação ambiental no Estado do Paraná, em solos não degradados. Documento 136, Embrapa Floresta, Colombo, PR, 2006.

CARVALHO, P. E. R. Espécies arbóreas brasileiras. v. 1. Embrapa Florestas. Brasília, DF, 2003. 1039 p.

CLEMENT, C. R. Melhoramento de espécies nativas. In: NASS, L. L. et al. (Eds.). Recursos genéticos e melhoramento - plantas. Rondonópolis: Fundação de Apoio à Pesquisa Agropecuária de Mato Grosso, 2001. p. 423-441.

FACHINELLO, J. C. et al. Propagação de plantas frutíferas. Brasília: EMBRAPA informações tecnológica, 2005, $221 \mathrm{p}$.

FERREIRA, B. G. A. et al. Miniestaquia de Sapium glandulatum (Vell.) Pax com o uso de ácido indolbutírico e ácido naftalenoacético. Ciência Florestal, Santa Maria, v. 20, n. 1, p. 19-31, 2010. FICK, T. A. Estabelecimento in vitro e propagação de Cordia trichotoma (Vell.) Arrabida ex Steudel (louro-pardo). 2007. 61 f. Dissertação (Mestrado em Engenharia Florestal) - Universidade Federal de Santa Maria, Santa Maria.

FRANZON, R. C. et al. Efeito do AIB e de diferentes tipos de estacas na propagação vegetativa da goiabeira-serrana (Acca sellowiana Berg). Revista Brasileira de Agrociência, Pelotas, v. 10, n. 4, p. 515-518, 2004.

GRATIERI-SOSSELLA, A. et al. Propagação da corticeira do banhado (Erythrina crista-galli L.) (Fabaceae) pelo processo de estaquia. Revista Árvore, Viçosa, v. 32, n. 1, p. 163-171, 2008.

HARTMANN, H. T. et al. Plant Propagation: principles and practices. 7. ed. New York: Prentice Hall, 2002. 880 p.

HEBERLE, M. Propagação in vitro e ex vitro de louro-pardo (Cordia trichotoma (Vell.) Arrabida ex Steudel). 2010. 76 f. Dissertação (Mestrado em Engenharia Florestal) - Universidade Federal de Santa Maria, Santa Maria.

HIGASHI, E. N. et al. Propagação vegetativa de Eucalyptus: princípios básicos e a sua evolução no Brasil. IPEF, Piracicaba, 2000. 14 p. (Circular Técnica n. 192).

HOPPE, J. M. et al. Influência do diâmetro de estacas no desenvolvimento dos brotos de Platanus $x$ acerifolia. Ciência Florestal, Santa Maria, v. 9, n. 1, p. 25-28, 1999.

IAPAR. Cartas climáticas do Paraná. Disponível em: $\quad<$ http://www.iapar.br/modules/conteudo/ conteudo.php? conteudo=597>. Acessado em: 08 de março de 2012.

INOUE, M. T.; PUTTON, V. Macropropagação de 12 espécies arbóreas da floresta ombrófila mista. Floresta, Curitiba, v. 37, n. 1, p. 55-61, 2007.

LORENZI, H. Árvores brasileiras: manual de identificação e cultivo de plantas arbóreas nativas do Brasil. $4^{a}$ ed. v. 1. Nova Odessa: Instituto Plantarum, 2002. $384 \mathrm{p}$.

MANTOVANI, N. C. et al. Regeneração in vitro de louro-pardo (Cordia trichotoma (Vellozo) Arrabida ex Steudel). Ciência Florestal, Santa Maria, v. 11, n. 2, p. 93-101, 2001.

MENDONÇA, E. A. F. et al. Viabilidade de sementes de Cordia trichotoma (Vellozo) Arrabida ex Steudel (louro pardo) pelo teste de tetrazólio. Revista Brasileira de Sementes, Pelotas, v. 23, n. 2, p. 64-71, 2001. 
MESÉN, F. Enraizamiento de estacas juveniles de espécies forestales: uso de propagadores de sub-irrigación. Turrialba: CATIE, 1997. $34 \mathrm{p}$.

NAZÁRIO, P. et al. Enraizamento de estacas de Luehea divaricata sob diferentes concentrações de ácido indolbutírico. Pesquisa Florestal brasileira, Colombo, n.54, p.139-143, 2007.

SAEG. SAEG: sistema para análises estatísticas, ver. 9.1. Viçosa: UFV, 2007.

TAIZ, L.; ZEIGER, E. Fisiologia Vegetal. 4 ed. Porto Alegre: Artmed, 2009. 848 p.

TOFANELLI, M. B. D. Enraizamento de estacas lenhosas e semilenhosas de cultivares de pessegueiro em diferentes concentrações de ácido indolbutírico. 1999. 87 f. Dissertação (Mestrado em Agronomia) - Universidade Federal de Lavras, Lavras.
WENDLING, I. et al. Produção de mudas de corticeira-do-banhado por miniestaquia a partir de propágulos juvenis. Embrapa Floresta, Colombo, 2005. 5 p. (Comunicado técnico n. 130).

WENDLING, I.; XAVIER, A. Gradiente de maturação e rejuvenescimento Aplicado em espécies florestais. Floresta e Ambiente, Seropédica, v. 8, n. 1, p. 187-194, 2001.

XAVIER, A. et al. Enraizamento de miniestaca caulinar e foliar na propagação vegetativa de cedro-rosa (Cedrela fissilis Vell.). Revista Árvore, Viçosa, v. 27, n. 3, p. 351-356, 2003.

XAVIER, A. et al. Silvicultura clonal: princípios e técnicas. Viçosa: UFV, 2009. 272 p.

ZUFFELLATO-RIBAS, K. C.; RODRIGUES, J. D.

Estaquia: uma abordagem dos principais aspectos fisiológicos. Curitiba: UFPR, 2001. 39 p. 